\title{
Study on the Health Status of Coastal People in Bangladesh After Cyclone Sidr and Aila
}

\author{
Russell Kabir \\ Senior Lecturer in Research Methods, Department for Allied and Public \\ Health, Anglia Ruskin University, UK \\ Hafiz T. A. Khan \\ Professor in Health, College of Nursing, Midwifery and Healthcare, \\ University of West London, UK
}

URL:http://dx.doi.org/10.19044/esj.2017.v13n15p10

\begin{abstract}
Bangladesh is recognized as one of the high-risk countries in the world that is prone to natural disasters. Due to its geographical location, topography, high population density, poverty and lower adaptive competence it is considered to be highly vulnerable to natural disasters in the world. This study was devised following the super cyclone Sidr that hit Bangladesh in November 2007 and cyclone Aila that hit in May 2009 to assess the impact of extreme weather event like cyclone on health of the coastal population of Bangladesh. A total of approximately 1000 households were selected by using the multistage cluster sampling technique from both villages. The study result shows that diarrheal, skin disease and mental health problems increased after the cyclones. The multivariable analysis shows that age of the respondents, gender, monthly income and educational level of the household heads and number of living children in the family have statistically significant effect on causing health problems before and after the cyclone Sidr and Aila. It can be concluded that extreme weather events like cyclones Sidr and Aila making the lives of the coastal people more difficult and also it increases the vulnerability in the society for poor people, elderly, children and women. Since this is a fairly unexplored research area, more empirical research work is needed to establish the impact of extreme weather events on health of the coastal people in Bangladesh.
\end{abstract}

Keywords: Coastal area, Bangladesh, Natural Disaster, Health, Cyclone

\section{Introduction}

Coastal area of Bangladesh is highly vulnerable area as it exposed to natural disasters due to recent climate change (Kabir et al, 2014). Bangladesh 
has been plagued by innumerable natural disasters over the years. So far the country has faced tropical cyclones, tidal surges, tornados, floods, droughts and river erosion. Over a period of 100 years, 508 cyclones have affected the Bay of Bengal region, 17 percent of which caused landfall in Bangladesh. A severe cyclone occurs almost once every three years. Although the frequency of cyclones is not unusual compared to other cyclone hotspot countries, the impact it causes stands out: 53 percent of the cyclones that claimed more than 5,000 lives took place in Bangladesh (GOB, 2008). The populations of the coastal regions of Bangladesh are living under the poverty line, for example Khulna and Barisal (southern part) and Rajshahi (northern part) and environmental degradation is one of the main reasons for poverty. The main occupations of the coastal people are farming, fishing and agricultural labourers whose livelihoods depend mainly upon the natural ecosystem (Akter, 2009). In recent years, Bangladesh was hit by two consecutive cyclones Sidr in 2007 and Aila in 2009. Paul (2009) found that cyclone Sidr which hit Bangladesh on 15 ${ }^{\text {th }}$ November 2007 caused 3,406 deaths and over 55,000 people sustained physical injuries. Heavy rain accompanying cyclones and tidal waves due to wind effects caused extensive physical destruction, casualties, damage of crops, livestock and flooding in total 30 districts across the South Western coastal district of Bangladesh (Ministry of Flood \& disaster Management, 2008). Cyclone Sidr affected nine districts of Bangladesh. The most devastated districts were Bagerghat, Barguna, Patuakhali and Pirojpur (Davidson, 2008). To find out the impact of natural disasters on health of the coastal population, the researcher decided to concentrate on the two major cyclones, which had recently hit Bangladesh, cyclone Sidr and Aila. There is growing scientific evidence from the literature that natural disasters are directly and indirectly affecting human health. The objective of this research is to assess the health effects of cyclones Sidr and Aila among the coastal people in Bangladesh.

\section{Methods}

This is a descriptive cross-sectional study. Data for the study were obtained from cyclone Sidr and Aila affected coastal populations in the South West part of Bangladesh. In Bangladesh, the administration is split into certain classified units and these units are divisions, districts, upazilas and unions and each village is governed by a Union (Haque et al, 2012). Barguna district was affected most by cyclone Sidr in 2007 (Kabir et al, 2014). Amtali upazila (consist of Baliatali and Gopkhali village) of Barguna District for data collection. Khulna was the other district selected for data collection. About 6 upazilas out of 9 in Khulna district was damaged by cyclone Aila in 2009 and Koyra was the most affected upazila (Roy et al, 2009). The Barabari village of Koyra Upazila of Khulna district was selected 
for data collection. A multistage cluster sampling design was used. The two districts Barguna and Khulna were the primary units. The sample size was determined by using the following cluster sampling Formula: $n=$ $z^{2} q / r^{2} p \times$ design effect $n=$ Required sample size, $Z=95 \%$ Confidence value $p=$ proportion of target population will be affected by the climate change $q=1-p$

$r=$ relative error which is assumed to be $8 \%$ (the lower is the value of $r$ the higher is the sample size; similarly, the higher is the value of $r$ the lower is the sample size)

In the absence of any information on $p$ we assume $p=50 \%$ $Z=1.96, p=.50, q=.50, r=8 \%$, assuming design effect $=1.5$

Putting the above values $\mathrm{n}$ is estimated as 600 . Now multiplying by design effect $1.5, n$ will be equal to 900 .

Considering non-response rate of about $10 \%$ the sample size was determined approximately 1000 .

The cluster is census enumeration area. A total of approximately 1000 households were selected by using the simple random sampling technique as tertiary units from the upazilas (secondary units) of these two districts. Data was collected using questionnaire survey from December 2011 to January 2012. The questionnaire was divided into 4 sections such as sociodemographic and household information, effects of natural disaster on household, effects of natural disaster on health and the last section was on pre-and post Sidr/Aila effects. The head of the household or family was given priority to respond to the questions. In the absence of the head, another other senior member of the family was given the opportunity. Particularly on health-related questionnaire all members of the family answered some question and on average an interview lasted for 30-45 minutes. To minimise the recall bias different questions were asked to the participant.

Data was analysed using the statistical package of social sciences (IBM SPSS) software version 21.

\section{Variables used in the analysis}

In this research variables are classified into two categories: (1) Demographic variables (2) Socioeconomic variables

\section{Demographic variables}

There are four demographic variables used in this analysis. These are:

1. The age of the household members (at the time of interview) in completed years. The age of the household head are classified into three groups on the basis of their age, i.e. below 5 years, 5-17 years and 18 years 
and above. It is understood that climate change has variable impacts on different age groups.

2. Gender of the household member is another demographic variable used in this research. Various literature on climate change and its impact has emphasized gender.

3. The number of children living in the family is categorized into four groups: none, 1 child, 2 children and 3 children or more.

4. The religion of the household head variable is classified into two categories: Muslim and Hindu.

5. Survey area: In this research the survey area is divided into categories: Cyclone Sidr affected area and cyclone Aila affected area.

\section{Socioeconomic variables}

The following socioeconomic variables are used in this research:

1. The level of education of the household head: in this research the level of education has been classified into three categories (i) no education (ii) primary education and (iii) secondary education and above.

2.Access to Television is defined as the dichotomy of yes and no.

3. Access to radio is also classified into two categories yes and no.

4.Electricity connection in the household is categorized in this research as yes and no.

5. Household monthly income is a very important factor in terms of climate change adaptation and health care. The household monthly income was classified into two income groups $<=3000$ Taka and $>3000$ Taka. (Taka is the name of the currency in Bangladesh. $1 \mathrm{USD}=77.95$ Taka as of 26 October 2013)

Here, occurrence of health problems before and after the disaster has been considered as the dependent variable. The occurrence of health problems before and after the disaster was measured by comparing the health problems faced by an individual before and after the disaster. If the health problems were higher after the disaster, then it was taken in to the consideration. The dependent variable is binary which is the occurrence of the health problems before and after the disaster. Its value is one whereas the occurrence of no health problem before and after the disaster is valued at zero. The independent variables used in this model are: age of the household head, gender of the member, number of children living in the family, religion of the household and survey area, level of education of household head, access to television, access to radio, electricity connection in the household, access to mobile phone and household monthly income. Considering all the variables in the Logit Model, we have: 
$\Rightarrow \ln \left(\frac{\rho_{i}}{1-\rho_{i}}\right)=\beta_{0}+\beta_{1}$ age $+\beta_{2}$ gender $+\beta_{3}$ number of children $+\beta_{4}$ religion $+\beta_{5}$ survey area $+\beta_{6}$ level of education $+\beta_{7}$ access to television $+\beta_{8}$ access to radio...+

Where $\mathrm{P}_{\mathrm{i}}=$ Probability that health problems occurred before and after disaster

$1-\mathrm{P}_{\mathrm{i}}=$ Probability that no health problem occurred before and after disaster

$\beta_{0}=$ Constant and $\beta_{1}, \beta_{2}, \beta_{3}, \beta_{4}, \beta_{5}, \beta_{6}, \beta_{7}$ are the co-efficients are to be estimated.

\section{Results}

Table 1 shows background characteristics of the respondents. About $52 \%$ respondents are from cyclone Sidr affected areas and 48.2\% respondents are from cyclone Aila affected areas. About $87.6 \%$ of respondents of the Household heads are male, $72.6 \%$ of households are Muslim followed by $27.4 \%$ of households are Hindu. The majority of the household heads (36\%) are aged over 50 years and only $22.6 \%$ are below 30 years. In both the cyclone-hit areas, 92\% of household heads are married; only $4.8 \%$ household heads are widowed. About $73.9 \%$ respondents are educated. Among them $43.5 \%$ respondents have studied up to primary level and $25.2 \%$ respondents have completed their secondary education. The statistics show that $44.2 \%$ of respondents have/had been living in the affected areas from 21 to 40 years and $15.6 \%$ respondents have/had been residing in the area for 61 to 80 years.

Table 1 Distribution of respondents by their characteristics

\begin{tabular}{ccc}
\hline Variables & Frequency & Percent \\
\hline Survey Area & & \\
Sidr & 504 & 51.8 \\
Aila & 469 & 48.2 \\
Gender of the Household Head & & \\
Male & 853 & 87.6 \\
Female & 120 & 12.3 \\
Age of the Household Head & & \\
$<30$ & 220 & 22.6 \\
$30-39$ & 196 & 20.1 \\
$40-49$ & 202 & 20.8 \\
50 above & 355 & 36.5 \\
Religious Status & & \\
Muslim & 706 & 72.6 \\
Hindu & 267 & 27.4 \\
\hline
\end{tabular}




\begin{tabular}{ccc}
\hline Marital Status & & \\
Married & 890 & 91.5 \\
Single & 20 & 2.1 \\
Divorced & 10 & 1.0 \\
Separated & 6 & 0.6 \\
Widowed & 47 & 4.8 \\
Educational Status & & \\
Yes & 719 & 73.9 \\
No & 254 & 26.1 \\
Level of Education & & \\
Primary Education & 424 & 43.5 \\
Secondary Education & 246 & 25.2 \\
Higher Secondary Education & 29 & 2.9 \\
Higher Secondary Education above & 20 & 2.1 \\
Living in this area & & \\
Less than a year & 9 & 0.9 \\
1-20 years & 79 & 8.1 \\
21-40 years & 430 & 44.2 \\
41-60 years & 297 & 30.5 \\
61-80 years & 152 & 15.6 \\
81-100 years & 6 & 0.6 \\
\hline
\end{tabular}

The logistic regression analysis shows that age, gender and religion of household member, access to electricity, monthly income, education level of the household head and number of living children in the family have a statistically significant effect on the occurrence of health problems before and after the disasters (Sidr and Aila). The odds ratio of the coefficient age indicates that household members whose aged 18 years and above their health problems is about eight times higher compared to the children aged under five years irrespective of before and after disaster. The analysis reveals that those households who had access to television compared to those who had no access to television were 20 percent higher chance of being affected by health problems before the disaster and those who had access to television were 66 percent less likely to have morbidity. The odds ratios also demonstrate that access to radio and TV are positively related with occurrence of health problems. These results are contrary to the Researcher's expectations and may be attributed to the small number of households possessing TV and radios and possibly the confounding effects of the radio and TV failed to capture expected direction of the relationships. Access to electricity is negatively associated with health problems as supported by the odds ratio. Households with electricity are $29 \%$ less likely to experience health problems that those who did not have access to electricity connection. Income status of the household has an important impact on the health problems. The higher the income the lower the probability of health problems. For example, households whose income are Taka 3000 and above 
their health problems are $19 \%$ lower than those households whose income is less than Taka 3000.The number of children in the households is positively associated with health problems. The higher is the number of children the higher the likelihood that they will suffer from health problems. As expected education level of the household head is negatively correlated with the health problems. The higher is the education level of the household head the lower the probability they will suffer from morbidity. For instance, household heads who had secondary education, had a $34 \%$ less probability of suffering from health problems than those who had no education.

Table 2 Odd ratio from logistic regression analysis assessing the association between explanatory variables and occurrence of health problem before and after the natural disaster

\begin{tabular}{cccc}
\hline & & \multicolumn{2}{c}{ Odd ratio (95\% C.I. for Odd ratio) } \\
\cline { 3 - 4 } Variables & Categorie & Occurrence of health & $\begin{array}{c}\text { Occurrence of health } \\
\text { problems before the disaster }\end{array}$ \\
problems after the disaster
\end{tabular}




\begin{tabular}{cccc}
\hline Survey area & Sidr & 1.00 & 1.00 \\
& Aila & $1.11(0.94-1.31)$ & $1.92(1.48-2.48)$ \\
& Constant & 0.10 & 2.04 \\
\hline & -2 Log & 5091.4 & 2819.3 \\
& likelihood & & 170.1 \\
Model & 202.2 & $\rho$-value $=<0.000$ \\
Chi- & $\rho$-value $=<0.000$ & \\
\hline
\end{tabular}

The logistic regression analysis also suggests mobile phones are not an important determinant of health problems since the odd ratio is found to be positive. The further analysis of logistic regression shows that males are more vulnerable to health problems after the disaster. It is revealed from the logistic regression coefficients that females were 12 percent less likely to have morbidity before the disaster while after the disaster females were 22 percent less likely to suffer from health problems. Similarly, religion of the household head shows that Hindus have a 28\% reduction in health problems compared to Muslims. As compared to Sidr area, respondents from Aila area had 2 times a higher risk of getting health problems after the natural disaster. The value of log likely $-2 \log$ likelihood Chi-square suggests model is well fitted and statistically significant $\rho$-value $=<0.000$.

\section{Discussion}

In this research, male respondents accounted for $87 \%$ and the vast majority of respondent were aged 50 years and above. About $74 \%$ of household heads revealed that they were educated and their main occupations were farming and fishing. A cross-sectional study conducted by Nesha et al, (2014) on people's perception about climate change and its adverse effect on rural Bangladesh reported that the age of the participants of the research was between 30 and 65 years, with about $51 \%$ respondents being female. Their main occupations were housewife, farming and private job. Similar findings are shown by Haque et al, (2012) and Karim et al, (2013). The monthly income of the respondents is less than 3000 Taka. This is consistent with other studies by Alam (2012) and Haque et al, (2012). Both Sidr and Aila affected people are aware of the fact that natural disasters due to climate change is affecting their health. Similar results were found by Bhuiyan and Khan (2011). The respondent household informed that the prevalence of skin diseases followed by infectious diseases and mental illness in the affected area. Paul et al, (2010) found in their study that after Sidr 38\% suffered diarrhoeal diseases, $12 \%$ suffered from typhoid and $4 \%$ skin diseases. When compared with the pre-and post effects of Sidr and Aila on diseases with the family members of the respondents' household it 
became clear that the prevalence of some diseases were very higher in the post cyclone period and some infectious diseases like diarrhoea which were not common before the cyclone, increased in incidence. Diarrhoeal disease outbreak occurred after the 2004 floods in Bangladesh, 1988,1998 and 2004 floods in Bangladesh, 2004 Tsunami in Indonesia, 2005 earthquake in Muzzafardbad Pakistan, floods in Mozambique 2000, floods in China and in USA after Hurricane Allison in 2001 and Katrina 2005 reported in WHO (2006), Schwartz et al, (2006), Ding et al, (2013) and Kondo et al, (2002). The chi-square analysis of this research displays that the percentage of diarrhoea was higher among individuals whose households' head had no formal education. This is consistent with another research on post cyclone Sidr illness in coastal Bangladesh where the researchers showed that the illness rate was higher among the illiterate population than the literate (Paul et al, 2010). Bhunia and Ghosh (2011) in their research after cyclone Aila in Sundarban of West Bengal, India reported an increased number of diarrhoea cases due to contaminated drinking water. Other health problems that are found significant in this research are respiratory problems, skin diseases, food poisoning, hepatitis and mental health problems. Waterborne diseases and skin infections were also reported in a study in the Delta State of Nigeria related to flooding (Emaziye, 2013). Hepatitis A and E were reported after the 2004 Tsunami in Indonesia (WHO, 2006), respiratory problems reported after the Tsunami and earthquake 2005 in Pakistan (WHO, 2006) and (Baqir et al, 2012). Dysentery cases were identified after flooding in Xinxian City, China (Ni et al, 2014). Diarrhea, skin and eye infections were identified in Pakistan after flood (Baqir et al, 2012). It also implies that irrespective of the type of disaster health problems following the occurrence of natural calamity is common. People of local communities should be provided primary health care support and knowledge in such situations to protect themselves from diarrhoea, skin diseases, food poisoning. Loss of family members, and a loss of employment due to damage to agricultural land and livestocks and reduced fish production are one of the contributing factors responsible for mental disturbance among the coastal communities. Similar results are in line with researches by Rahman et al, (2014), Swim et al, (2009) and Kazdin (2009).

\section{Conclusion}

There is limited research on understanding the likely health impacts on coastal population of natural disasters. The research gaps and other information provided in this research leads to a great number of potential research ideas. Knowledge and awareness on natural disasters like cyclones related threats should be made available for the coastal population. In addition, research should be carried out to assess the current knowledge and 
awareness of natural disasters and its impact of the coastal communities to address the gaps. To reduce the vulnerability of costal communities' capacity building programmes should be run at household levels to adapt with disasters and different livelihood strategies. Adaptation measures at community level will help local people to strengthen their barriers against disasters. The coast of Bangladesh is a densely populated area and relocation of coastal people is not possible due to land availability. So it's a high priority that local people should know about the management natural disaster impacts. The coastal zone should be protected where it is environmentally viable. This research has collected information on the other members of the households by questioning the head of the households. This has its inherent limitations as it relies on the knowledge of the respondents. The small sample size of the research is another limitation because it does not allow generalization of the descriptive findings.

\section{Ethical Approval}

The study protocol was approved by Middlesex University Ethics Review Committee.

\section{Competing Interests}

The authors declared that there are no potential competing interests with respect to the research, authorship, and/or publication of this paper.

\section{Acknowledgements}

This is an outcome of the Dr. Russell Kabir's PhD thesis submitted to Middlesex University in London and all authors are directly contributed to this research.

\section{References:}

1. Akter, T. (2009). Climate change and flow of environmental displacement in Bangladesh. [Online] Available at: http:// www.unnayan.org. [Accessed on 05/12/2015]

2. Alam, M.R. (2012). Climate change and its impact on health and livelihood within Hatiya Island of Bangladesh. Journal of Agroforestry Environment, 6 (2): 13-16.

3. Baqir, M., Sobani, Z. A., Bhamani, A., Bham, N. S., Abid, S., Farook, J., \& Beg, M. A. (2012). Infectious diseases in the aftermath of monsoon flooding in Pakistan. Asian Pacific journal of tropical biomedicine, 2(1), 76-79.

4. Bhuiyan, S. H. and Khan, H. T. A. (2011). Climate Change and its Impacts on Older Adults' Health in Kazakhstan. The NISPAcee Journal of Public Administration and Policy, IV (1); 97-119. 
5. Bhunia, R., and Ghosh, S. (2011). Waterborne cholera outbreak following Cyclone Aila in Sundarban area of West Bengal, India, 2009. Transactions of the Royal Society of Tropical Medicine and Hygiene, 105;214-219.

6. Davidson, S. (2008). A Review of the IFRC-led Shelter Coordination Group Bangladesh Cyclone Sidr Response 2007-2008.

7. Ding, G., Zhang, Y., Gao, L., Ma, W., Liu, X., Liu, Q., and Jiang, B. (2013).Quantitative analysis of burden of infectious diarrhoea associated with flood in Northwest of Anhui Province, China: A mixed method evaluation. PLOS one, 8(6). [Online] Available at: http://www.plosone.org [Accessed on 13/07/2014]

8. Emaziye, P. O. (2013). Food Security Index and Socio-Economic Effects of ClimateChange on Rural Farming Households in Delta State, Nigeria. Asian Journal of Agriculture and Rural Development, 3(4): 193-198.

9. GoB. (2008). Cyclone Sidr in Bangladesh: Damage loss and Needs Assessment for Disaster Recovery and Reconstruction. Dhaka, Bangladesh.

10. Haque, U., Hashizume, M., Kolivras, N.K., Overgaard, J. Hans., Das, B., Yamamoto, T. (2012). Reduced death rates from cyclones in Bangladesh: what more needs to be done? Bulletin of World Health Organization, 90:150-156.

11. Kabir, R., Khan, H.T.A., Ball, E., \& Caldwell, K. (2014). Climate Change and Public Health Situations in the Coastal Areas of Bangladesh. International Journal of Social Science Studies,2(3): 109-116.

12. Karim, R., Mohinuzzaman, M., Rahman, S., and Rani, A. (2013). Impacts of Climate Change and Socio-Economic Sector and Health profile in the interior Coast, Bangladesh: the case study of Dumuria Upazila, Khulna, Bangladesh. IOSR Journal of Environmental Science, Toxicology and Food Technology, 5 (1):38-46.

13. Kazdin, A.E. (2009). Psychological science's contributions to a sustainable environment: Extending our reach to a grand challenge of society. American Psychologist,64(5):339-356.

14. Kondo, H., Seo, N., Yasuda, T., Hasizume, M., Koido, Y., Ninomiya, N., \&Yamamoto, Y. (2002). Post-flood-infectious diseases in Mozambique. Prehospital and disaster medicine, 17(03):126-133.

15. Ministry of food and disaster management (2008). Major natural disaster in Bangladesh [Online] Available at: http://www.dmb.gov.bd/pastdisaster.html [Accessed on 25/09/2014]. 
16. Nesha, K., Rahman, A.A., Hasan, K., and Ahmed, Z. (2014). People's perception in relation to climate change and its adverse effect in rural Bangladesh. Journal of Environment and Human, 1(3):23-33.

17. Ni, W., Ding, G., Li, Y., Li, H., and Jiang, B. (2014). Impacts of floods on dysentery in Xinxiang city, China, during 2004-2010: a time series Poisson analysis. Global Health Action, 7:23904 [Online] Available at: http://www.globalhealthaction.net/ [Accessed on $13 / 08 / 2014]$

18. Paul B.K. (2009). Why relatively fewer people died? The case of Bangladesh's cyclone Sidr. Natural Hazards, 50:289-304.

19. Paul, B.K., Rahman, M.K., Rakshit, B.C. (2010). Post-Cyclone Sidr illness patterns in coastal Bangladesh: an empirical study. Natural Hazards, 56:841-852.

20. Rahman, M.S., Mohamad, O.S., and Zarim, Z.B.A. (2014). Climate Change: A review of its health impact and perceived awareness by the young citizens. Global Journal of Health Sciences, 6(4):196-204.

21. Roy, K., Kumar, U., Mehedi, H., Sultana, T. and Ershad, D. M. (2009). Initial Damage Assessment Report of Cyclone AILA with focus on Khulna District. Unnayan Onneshan-Humanity WatchNijera Kori, Khulna, Bangladesh, June 23, 2009. pp-31.

22. Schwartz, B.S., Harris, J.B., Khan, A.I., Larocque, R.C., Sack, D.A., Malek, M.A., Faruque, A.S.G., Qadri, F., Calderwood, S.B., Luby, S.P., Ryan, E.T. (2006). Diarrhoeal epidemics in Dhaka, Bangladesh, during three consecutive floods: 1988, 1998, and 2004.American Journal of Tropical Medicine and Hygiene, 74(6): 1067-1073.

23. Swim, J., Clayton, S., Doherty, T., Gifford, R., Howard, G., Reser, J.,Stern, P., and Weber, E.(2009). Psychology and global climate change: Addressing a multifaceted phenomenon and set of challenges. Washington, D.C, American Psychological Association.

24. WHO. (2006). Communicable diseases following natural disasters: Risk assessment and priority interventions. [Online] Available at: http://www.who.int/diseasecontrol_emergencies/en/ [Accessed on 27/07/2014] 